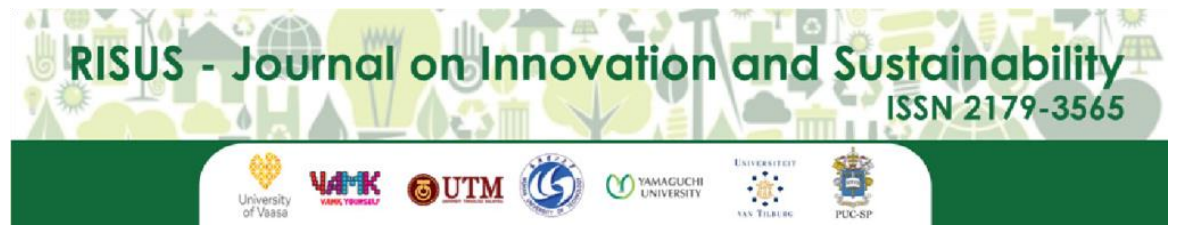

RISUS - Journal on Innovation and Sustainability volume 11, número 1 - 2020 ISSN: $2179-3565$

Editor Científico: Arnoldo José de Hoyos Guevara Editor Assistente: Rosa Rizzi Avaliação: Melhores práticas editoriais da ANPAD

\title{
GHANA'S ROAD TO CASHLESS ECONOMY: THE E-ZWICH EXPERIENCE
}

\author{
O Caminho de Gana para uma economia sem dinheiro: a experiência E-zwich
}

\author{
Bismark Addai ${ }^{1}$, Benedict Arthur $^{2}$ \\ 12Zhongnan University of Economics and Law \\ e-mail: abismarks@hotmail.com,bukyee@outlook.com
}

\begin{abstract}
In 2008, the Government of Ghana (GoG) through the Bank of Ghana (BoG) and Ghana Interbank Payment and Settlement System (GHIPSS) launched a smart card called e-zwich which formed a central part of the government's plan to move the country towards a cashless economy. Modernization of the cash sector has remained at best in a confused state since it was launched and at worst an embarrassing drawback. In this article, we employ the Unified Theory of Acceptance and Use of Technology (UTAUT) and the structural equation model to estimate users' behavioral intentions and actual usage of the cashless system. The structural results show that eleven out of the fourteen hypotheses are statistically significant, while the remaining three are statistically insignificant. The results also indicate that performance efficiency, effort efficiency, and social influence significantly influence the behavioral intentions of people to use the cashless system, and the age and gender of users significantly moderate the three constructs. Behavioral intentions and facilitating conditions are also found to influence actual usage of the cashless system significantly. This study fills the gap in the applicability of the UTAUT model in a central cashless system acceptance and usage. The study also provides empirical evidence on how demographic factors such as age, education, and gender moderate the relationships among the major constructs of the UTAUT model. For the first time, we support the empirical findings on the moderating effect of age in the UTAUT model with established economic theory, the life-cycle theory. We have outlined recommendations in detail on some important considerations needed to achieve smart financial economy in Ghana, and such achievement could be emulated by other countries that are yet to implement a central cashless system.
\end{abstract}

Keywords: Cashless economy; Non-cash payment; E-zwich; UTAUT model; Life-cycle theory.

\section{ACEITO EM: 30/01/2020 \\ PUBLICADO: 30/05/2020}




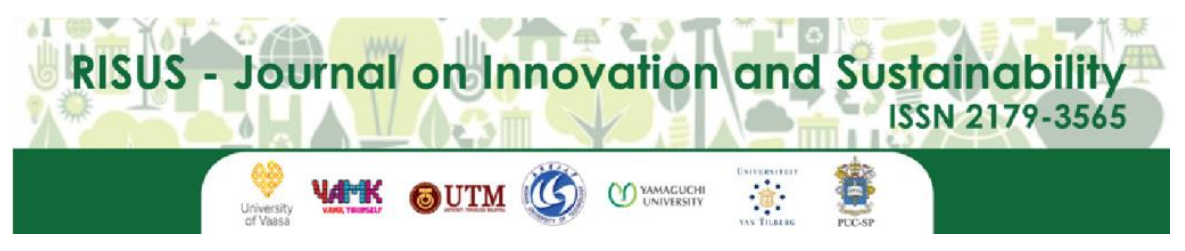

RISUS - Journal on Innovation and Sustainability volume 11, número 1 - 2020 ISSN: $2179-3565$ Editor Científico: Arnoldo José de Hoyos Guevara Editor Assistente: Rosa Rizzi Avaliação: Melhores práticas editoriais da ANPAD

\title{
O CAMINHO DE GANA PARA UMA ECONOMIA SEM DINHEIRO: A EXPERIÊNCIA E-ZWICH
}

\author{
Ghana's road to cashless economy: the E-Zwich experience
}

\author{
Bismark Addai ${ }^{1}$, Benedict Arthur $^{2}$ \\ 12Zhongnan University of Economics and Law \\ e-mail: abismarks@hotmail.com, bukyee@outlook.com
}

\section{RESUMO}

Em 2008, o Governo de Gana (GoG), através do Banco de Gana (BoG) e do Sistema Interbancário de Pagamentos e Liquidação de Gana (GHIPSS) lançou um cartão inteligente chamado e-zwich, que formava uma parte central do plano do governo de mover o país para uma economia sem dinheiro. A modernização do setor de caixa permaneceu na melhor das hipóteses em um estado confuso desde que foi lançada e, na pior das hipóteses, uma desvantagem embaraçosa. Neste artigo, empregamos a Teoria Unificada de Aceitação e Uso de Tecnologia (UTAUT) e o modelo de equações estruturais para estimar as intenções comportamentais dos usuários e o uso real do sistema sem dinheiro. Os resultados estruturais mostram que onze das quatorze hipóteses são estatisticamente significativas, enquanto as três restantes são estatisticamente insignificantes. Os resultados também indicam que a eficiência no desempenho, a eficiência no esforço e a influência social influenciam significativamente as intenções comportamentais das pessoas em usar o sistema sem dinheiro, e a idade e o sexo dos usuários moderam significativamente os três constructos. As intenções comportamentais e as condições facilitadoras também influenciam significativamente o uso real do sistema sem dinheiro. Este estudo preenche a lacuna na aplicabilidade do modelo UTAUT em uma aceitação e uso de um sistema central sem dinheiro. O estudo também fornece evidências empíricas sobre como fatores demográficos, como idade, educação e gênero, moderam as relações entre as principais construções do modelo UTAUT. Pela primeira vez, apoiamos as descobertas empíricas sobre o efeito moderador da idade no modelo UTAUT com a teoria econômica estabelecida, a teoria do ciclo de vida. Descrevemos detalhadamente as recomendações sobre algumas considerações importantes necessárias para alcançar uma economia financeira inteligente no Gana, e essa conquista pode ser imitada por outros países que ainda não implementaram um sistema central sem dinheiro.

Palavras-chave: Economia sem dinheiro; Pagamento não em dinheiro; E-zwich; Modelo UTAUT; Teoria do ciclo de vida. 


\section{INTRODUCTION}

Money has evolved from the era of cowries, shells, coins, papers (banknotes) to contemporary electronic or digital currency. The 21 st century popularly known as the computer age has seen the proliferation of digital money. At present, it is sufficient to swipe a plastic card in a bus, at a shop, hotel, restaurant or press a button on a smartphone to effect payment and the necessary amount will be deducted without the need for physical cash. Digital money is the new normal in the world of commerce especially in developed and some developing economies owing to its profound socio-economic impacts besides security, convenience and cost reduction advantages enshrined in its usage.

In developed countries, most nations are fully embracing the idea of a comprehensive cashless economy. It is increasingly becoming unusual to see customers pull out cash from their wallets to effect payment. In a country like Sweden, more than 59 percent of consumer transactions are completed via non-cash methods, according to the research conducted by Forex Bonuses in 2017. In the United State of America, digital payment mostly via credit cards has been part of their culture for years, and according to Forex Bonuses, each individual within the state possesses about three credit cards.

Realizing the benefits of cashless economy against the cost and risk of cash payments, even developing economies like Nigeria, India, China just to mention a few have joined the chariot heading towards a cashless society. Nigeria, as part of its diverse effort towards attaining a cashless economy, launched a state card pilot program in August 2014. This payment card grants financial support to 13 million Nigerians via a digital payment system according to the press release of MasterCard in the year 2014. Similarly, cashless transaction is taking hold in India, where previously only close to 5 percent of the country's transactions was cashless (MasterCard, 2015).

Though a cashless society in developing countries seems to be a distant dream, the account of China depicts otherwise. China's favorable policies in financial technology such as the Broadband China Strategy and Implementation Plan has helped in accelerating the nation to an almost-cashless society (China Briefing, 2013). There is a drastic fall in cash transactions in the country as a result of mammoth usage of mobile applications such as Alipay and Wechat for transactions. According to Payment and Clearing Association of China's data from 2013 to 2016, non-banking mobile application transactions have increased from 3.777 billion Yuan to over 97 billion Yuan, with a compound annual growth rate of over 195 percent.

Ghana, one of the fastest developing countries in West Africa, has also long recognized the need to revolutionize the financial sector to truncate the cash-dependent transactions. The central bank of Ghana (BoG) in collaboration with Ghana Interbank, Payment and Settlement Systems (GhIPSS) took the initiative to introduce a system where myriad cashless transactions can be done using a biometric smartcard called e-zwich card, which was officially launched in the year 2018. The card wss designed to provide a common podium to harmonize payment systems of all banks and other financial intuitions in the country, and to also help reach both underbanked and unbanked sectors of the economy by promoting branchless banking and financial inclusion (Ackorlie, 2009).

The implementation of the e-zwich seems not to be going as planned by GhIPSS though the e-zwich was seen to hold the promise for a cashless society in Ghana. Transformation of the cashless sector remained at best in a confused state and at worst an awkward drawback. The devastating situation has forced users to snub the ezwich smart card which has failed to bring relief and comfort in carrying out cashless transactions in the country and also to steer the country into a cashless financial society. Refusal of certain shop attendants to introduce the e-zwich card to their customers as an alternative source of payment, broken down of point of sale devices, low patronage, and recursive failure of mobile network connectivity are but a few of the reasons (Accra Daily Mail, 2010). As of today, many people either do not know about the existence of the card or do not want anything to do with the card even after several attempts of government to make the usage of the card compulsory for civil servants and national service personnel. Consequently, Ghana's hope of attaining a cashless economy on the ticket of e-zwich initiative is dwindled and thus leaving many in doubt about the country's readiness for a cashless economy. 
Mobile money (Momo) is the latest cashless media introduced to Ghana by telecommunication companies. Mobile money transaction was started by MTN telecom company in the year 2009 and later telecom companies such as TIGO, AIRTEL and VODAFONE joined. Mobile money services are offered to the subscribers of the telecom industry in conjunction with banks. The worth of mobile money transactions in the country reached GHф 19.6 million just after three years of its inception (Bank of Ghana, 2012). In 2017, mobile money saturation fully-fledged significantly to $\mathrm{GH} \phi 155.8$ billion in mobile transactions from $\mathrm{GH} \phi 78.5$ billion in 2016. In spite of the great impact of mobile money transfer as a cashless media, many Ghanaians are still reluctant to use this media as a result of security, and cost issues inherent in its usage. The gov't led cashless system, the e-zwich could be an ideal cashless platform for Ghanaians given that it is more secure and affordable than mobile money platforms recently introduced into the country by telecom companies.

In the light of the above argument, we employ the UTAUT model to assess users' behavioral intentions and actual usage of the cashless system and how demographic factors moderate the relationship. We also explain our empirical results in the lens of the life-cycle theory. The main contributions of this study are in three folds: First, this study provides fresh insight into the applicability of the UTAUT model in the acceptance and usage of a government-led cashless system and the factors that drive the usage or non-usage cashless monetary system. Second, we provide empirical evidence on how demographic factors such as age, education, and gender moderate the relationships among the major constructs of the UTAUT model. Finally, for the first time, we support the empirical findings on the moderating effect of age in the UTAUT model with established economic theory, the life-cycle theory. The next section of the study presents the theoretical review and development of hypothesis. Section three discusses the research methodology including the conceptual model (framework), data sampling, data sources, and analytical tools. Section four discusses the empirical results while Section five presents conclusion and recommendation.

\section{THEORETICAL REVIEW AND DEVELOPMENT OF HYPOTHESES}

The Unified Theory of Acceptance and Use of Technology (UTAUT) is a technology acceptance model synthesized by Venkatesh et al. (2003) to explain what influences people to accept and use technology in the workplace. As the name suggests, the model is an amalgamation of constructs of the earlier researched and developed models on individual acceptance and use of information technology such as theory of reasoned action, technology acceptance model, and motivational model, theory of planned behavior and diffusion of innovations theory. The synthetization feature of UTAUT gives it an added advantage over other models since it provides extensive insight into the factors of behaviour of acceptance and use of new technologies (Venkatesh et al. 2003; Kripanont 2007). The UTAUT recognizes four major factors namely performance expectancy, effort expectancy, social influence, and facilitating conditions alongside four moderators (i.e., age, gender, experience, and voluntariness) which are theorized to moderate the impact of the four key constructs on predicting behavioral intention to use a technology and actual technology usage.

According to Venkatesh et al 2003, Performance expectancy (PE) is "the degree to which the user expects that using the system will help him or her to attain gains in job performance". That is, the use of a particular system will help satisfy a desired need of a user. Thus, a system that doesn't help users to meet their job demands or needs is highly to be rejected by users (Fang et al. 2005). Performance Expectancy is proven by many authors and researchers to be the key belief factor that influences positively user's decision to use or accept a new technology (Venkatesh et al. 2003; Figl and Derntl, 2011; Yakubu 2012, Khayati and Zouaoui; and 2013 Omol et al. 2016). Consequently, the researcher hypothesizes that, H1: Performance expectancy has a positive effect on the behavioral intention to use Ezwich.

Effort expectancy (EE) is the second construct of the UTAUT model. According to Venkatesh et al. (2003), effort expectancy refers to "the degree of ease associated with the use of the system". That is, freedom from difficulty or great cognitive effort. The validity of effort expectancy on behavior intention just like performance expectancy has been confirmed consistently by several researchers in both mandatory and voluntary setups (Venkatesh et al. 2003, Chang et al. 2007; Yakubu, 2012; and Shibl et al 2013). For instance, 
Phichitchaisopa and Naenna (2013) established effort expectancy has a positive influence on adoption of healthcare technology in their study conducted Thailand. H2: Effort Expectancy has a positive effect on the behavioral intention to use Ezwich.

Social influence (SI) according to Venkatesh et al. (2003), is "the degree to which an individual perceives that important others believe he or she should use the new system." That is, the extent to which people align themselves to the believes or perceptions of others about them. According to Venkatesh et al. (2003), UTAUT social influence in a voluntary setting was found to be insignificant during the validation test, but significant in a mandatory context. Pynoo et al 2012; Cilliers and Flowerdays 2014; Alaiad and Zhou, (2014) found social influence to be a relevant interpreter of user's behavioral intention to use a new technology. According to Chang et al., 2007; and Phichitchaisopa and Naenna, 2013, the insignificance of UTAUT social influence on behavior intention can be attributed to the timing of the study and the personality of participants. Thus, the degree at which users will turn to adopt ezwich which is a partly mandated new technology is positively correlated with social influence. H3: Social Influence has a positive effect on the behavioral intention to use Ezwich.

The fourth construct, facilitating conditions (FC), together with behavior intentions directly influence the actual usage of a technology. FC, according to Venkatesh, et al (2003), "is the degree to which an individual believes that an organizational and technical infrastructure exists to support the use of a system." The authors assert that FC is insignificant in predicting behavior intention to use a technology but rather actual usage because FC seems to be fully moderated by effort expectancy. Facilitating conditions construct of UTAUT model was also proven significant in both voluntary and mandatory settings upon validation test according to Venkatesh, et al (2003). Several studies (Chang et al., 2007; Bennani and Oumlil, 2013; Phichitchaisopa and Naenna, 2013, and Tabassum et al. 2015) have also produced similar conclusion on the fact that facilitating conditions has a direct influence on actual usage of a technology. In this light, the researcher hypothesizes that facilitating conditions and behavioral intentions positively affects the actual usage of a cashless system. The hypotheses are as follows.

H4: Facilitating conditions has a positive effect on the actual usage of Ezwich. H5: Behavioral intention has a positive effect on the actual usage of Ezwich.

According to the UTAUT model, the structure of a population of users turn to moderate the significant impact of the main constructs on behavior intention to use a new technology. As such, Venkatesh, et al. (2003) propounded, tested and found significant four main moderators (age, gender, experience and voluntariness) on the main constructs. However, due to heterogeneity in studies, the differences in the study areas and most importantly the gap in literature, this study employed gender, age, and education as moderators on the three main construct as opposed to the four main moderators propounded by Venkatesh, et al. (2003). According to Cirasino and Garcia, (2008), actual conditions that influences payment system design and products are subjected to individual or local country's environmental conditions such as physical, social and cultural factors despite the universal consensus on some of the features of a payment system. Hence, the researchers develop the following further hypotheses:

H6a: The effect of performance expectancy on the behavioral intention to use ezwich is expected to be moderated significantly by age.

H6b: The effect of performance expectancy on the behavioral intention to use ezwich is expected to be moderated significantly by gender.

H6c: The effect of performance expectancy on the behavioral intention to use ezwich is expected to be moderated significantly by education.

H7a: The effect of effort expectancy on the behavioral intention to use ezwich is expected to be moderated by age.

H7b: The effect of effort expectancy on the behavioral intention to use ezwich is expected to be moderated significantly by gender.

H7c: The effect of effort expectancy on the behavioral intention to use ezwich is expected to be moderated significantly by education.

H8a: The effect of social influence on the behavioral intention to use ezwich is expected to be moderated significantly by age. 
H8b: The effect of social influence on the behavioral intention to use ezwich is expected to be moderated significantly by gender.

H8c: The effect of social influence on the behavioral intention to use ezwich is expected to be moderated significantly by education.

The various scholarly cradles reviewed show a gap in literature which this study aims to fill. Despite the robustness of the UTAUT and its validity in different settings, no scholar has attempted to expand its capability to predict users' acceptance behavior about a cashless system, left alone government led cashless system. Lastly, this study assesses the effect of demographics (age, gender and education) on the main construct in influencing user behavioral intention to use the ezwich to offer an explanation for the moderating effect of age based on the life-cycle theory.

\section{The research framework}

The framework below illustrates the relationship and moderation of gender, age and education on the effects of the four predictors on behavioral intention and usage of e-zwich.

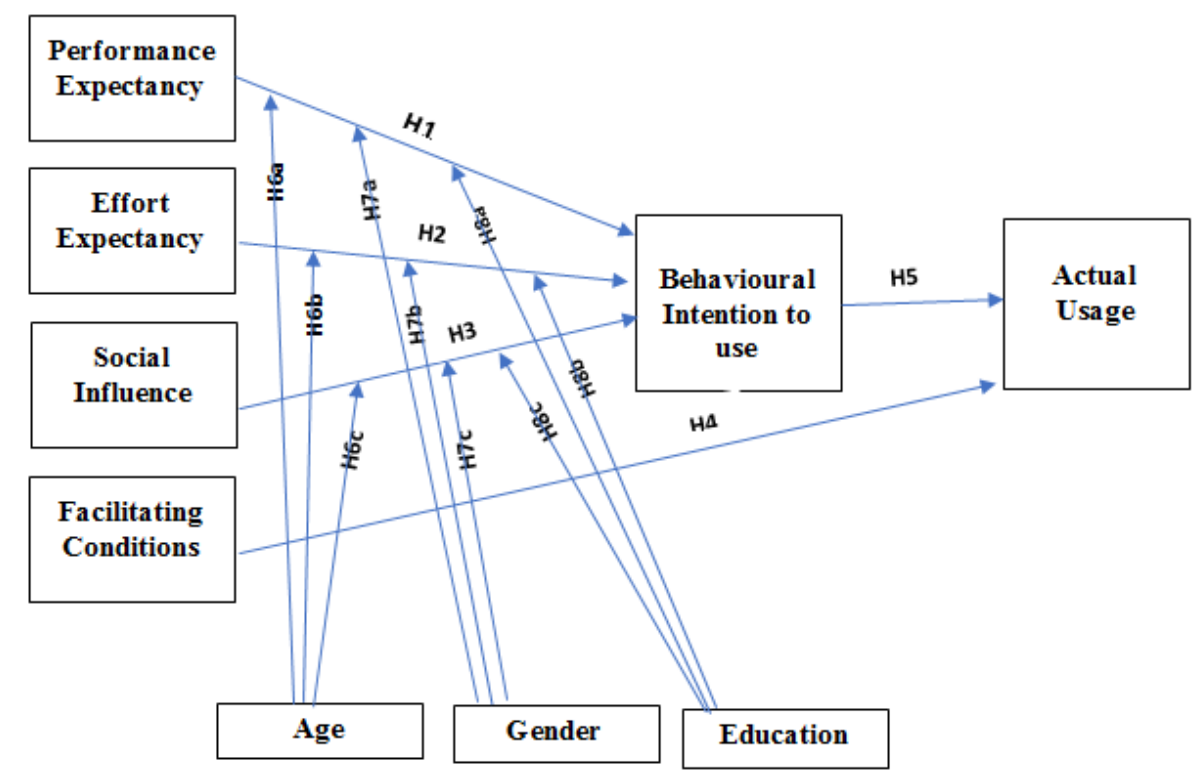

Figure 1. The modified UTAUT model based on Venkatesh, et al. (2003)

\section{The life-cycle theory}

The life-cycle theory assumes that individuals and households are concerned about long-term consumption opportunities and therefore explain consumption and savings in terms of expected future income. The original theory offers a specific account of consumption and saving; but it is derived from fundamental underlying principles that could be used to extend the model to deal with a wide range of issues about consumption and saving (Modigliani \& Brumberg, 1954). The thrust of the theory is that young people generally have low incomes but they have big spending commitments such as investing in their human capital through training and education, buying a home, and building a family. Thus, young people tend to borrow more, spend more, and save less. On the other hand, as people get older, their income generally increases and they pay off their loans and mortgages, and they prepare for retirement, so they increase their savings and 
investment and reduce consumption of certain commodities. We extend this theory to support the empirical findings of this study that age significantly moderates users' intention to use a cashless system.

\section{RESEARCH METHODOLOGY}

This study targeted the population of all e-zwich card bearers living in five of the most developed metropolises in Ghana: Accra, Kumasi, Cape coast, Obuasi, and Sunyani. The e-zwich involves financial architecture for its operation and the architecture is very functional in these five metropolises. A total sample of five hundred respondents (hundred respondents from each metropolis) were engaged in this study. Primary data was mainly utilized in this study and a structured questionnaire was used as the main instrument for collecting the quantitative data. The questionnaire contained close-ended questions and respondents were asked to choose from a fixed set of answers indicative of their opinions on the usage and challenges associated with the e-zwich. Based on the study conducted by Venkatesh et al. (2003) responses on all the UTAUT constructs in this study were measured with a five-point Likert scale rating, where strongly disagree $=1$; disagree $=2$; neutral $=3$, agree $=4$; Strongly agree $=5$. For the actual usage construct, in this study we also collected demographic data of the respondents to moderate the various UTAUT constructs to specifically measure behavioral intentions and usage of the payment system among people with varying backgrounds. The data collection spanned a period of seven months (from February to August, 2019).

\section{DATA ANALYSIS AND DISCUSSION}

Out of the 500 questionnaires administered to respondents, 495 questionnaires were completed and this constitutes response rate of $99 \%$. The completed questionnaires have been analyzed in this section of the article. All the analyses in this article were done using SmartPLS and IBM SPSS statistical applications. The SmartPLS was mainly used for the structural equation modeling which includes the reliability and validity of the constructs, evolution of the model fit, the structural model and the testing of hypotheses.

\subsection{Demography of the respondents}

The demographic characteristics of the people involved in this study are presented in Table 1 below.

Table 1. Demographic characteristics of the sample

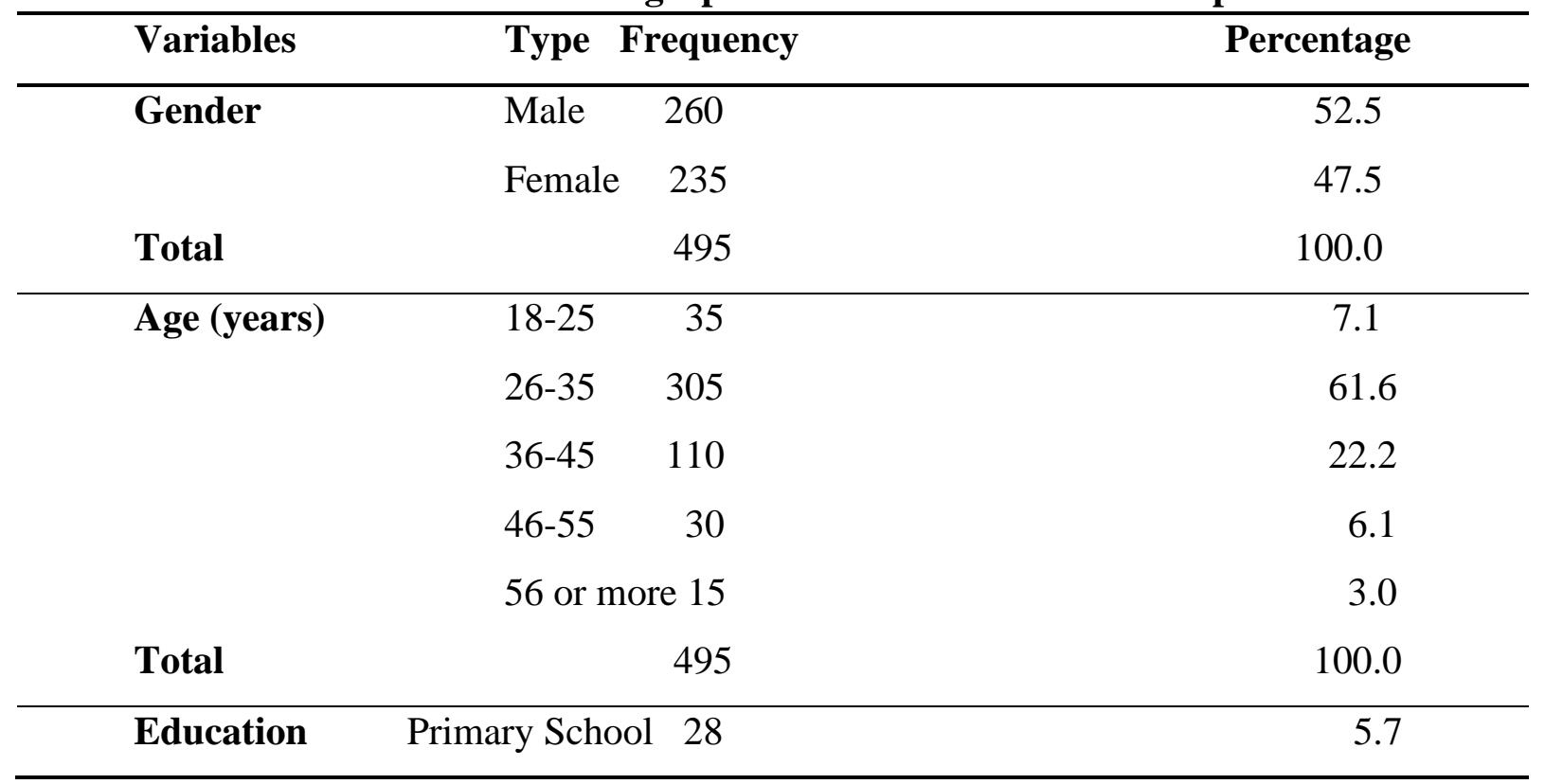




\begin{tabular}{|c|c|c|}
\hline & JHS Certificate 42 & 8.5 \\
\hline & Vocational Certif.38 & 7.7 \\
\hline & Training College certif. 47 & 9.5 \\
\hline & Bachelor and above $\quad 340$ & 68.7 \\
\hline Total & 495 & 100.0 \\
\hline
\end{tabular}

Table 1 depicts that 260 (52.5\%) males and 235 (47.5\%) females constituted the study sample. The results also show that $305(61.6 \%)$ of the respondents were 26-35 years old, 110 (22.2) were 36-45 years old, 35 $(7.1 \%)$ were within the age bracket of $18-25$ years, 30 (6.1) were 46-55 years old while $15(3.0 \%)$ were 56 years old and above. The age distribution of the respondents indicates that most of the respondents were in the age bracket of 26-45 years old. The results further indicate that $340(68.7 \%)$ of the respondents have obtained at least Bachelors degree, 47 (9.5\%) have training college certificates, 42(8.5) have Junior High School certificates, 38 (7.7\%) have Senior High School/Vocational school certificates while 28 (5.7) have only completed primary school.

\subsection{Construct reliability}

The reliability of the indicators used for the constructs in this study was tested in order to remove items that do not contribute significantly to the various contracts. Three forms of reliability tests were done in this study: indicator reliability, composite and Cronbach alpha reliability. The indicator reliability (outer loading consistency) was performed to find out the strength of item or indicator and how they contribute to the respective constructs. Three types of reliability test were employed. The indicator reliability was obtained by squaring the outer loadings of the indicators (items) and the values obtained were then compared with acceptable level for indicator reliability. Hair et al. (2012) have established that the minimum indicator reliability must be greater than the 0.4 acceptable level. For this study, the threshold reliability indicator is 0.5 and values above the threshold were considered reliable. However, one of the indicators for Social Influence, SI4 was dropped because of its weak factor loading of 0.325). After the weak indicator was dropped, the model was tested again to get a new measurement scale. The composite and Cronbach alpha reliability tests were also done to check the internal reliability (consistency) of the constructs. According to Hair et al. (2014), the combination of indicators embodying a particular construct must have a reliability value of 0.7 and values higher than that are considered reliable even though other studies (Hair et al., 2013; Bagozzi and Yi, 1988) permit lesser values including 0.6. As illustrated in Table 2, it is evident that the reliability values of all the constructs are higher than 0.8 as indicated by both composite reliability and Cronbach, thus, the study constructs as said to be consistent and reliable.

Table 2. Construct Reliability (Convergent and Discriminant validity)

\begin{tabular}{llrrrr}
\hline Construct & Indictor & Loadings & $\begin{array}{l}\text { Indicator } \\
\text { Reliability } \\
\left(\text { loading }^{2}\right)\end{array}$ & Cronbach & $\begin{array}{r}\text { Composite } \\
\text { reliability }\end{array}$ \\
\hline Performance & PE1 & 0.753 & 0.5665 & 0.915 & 0.937 \\
Expectancy & PE2 & 0.855 & 0.7315 & & \\
(PE) & PE3 & 0.916 & 0.8396 & & \\
\hline
\end{tabular}




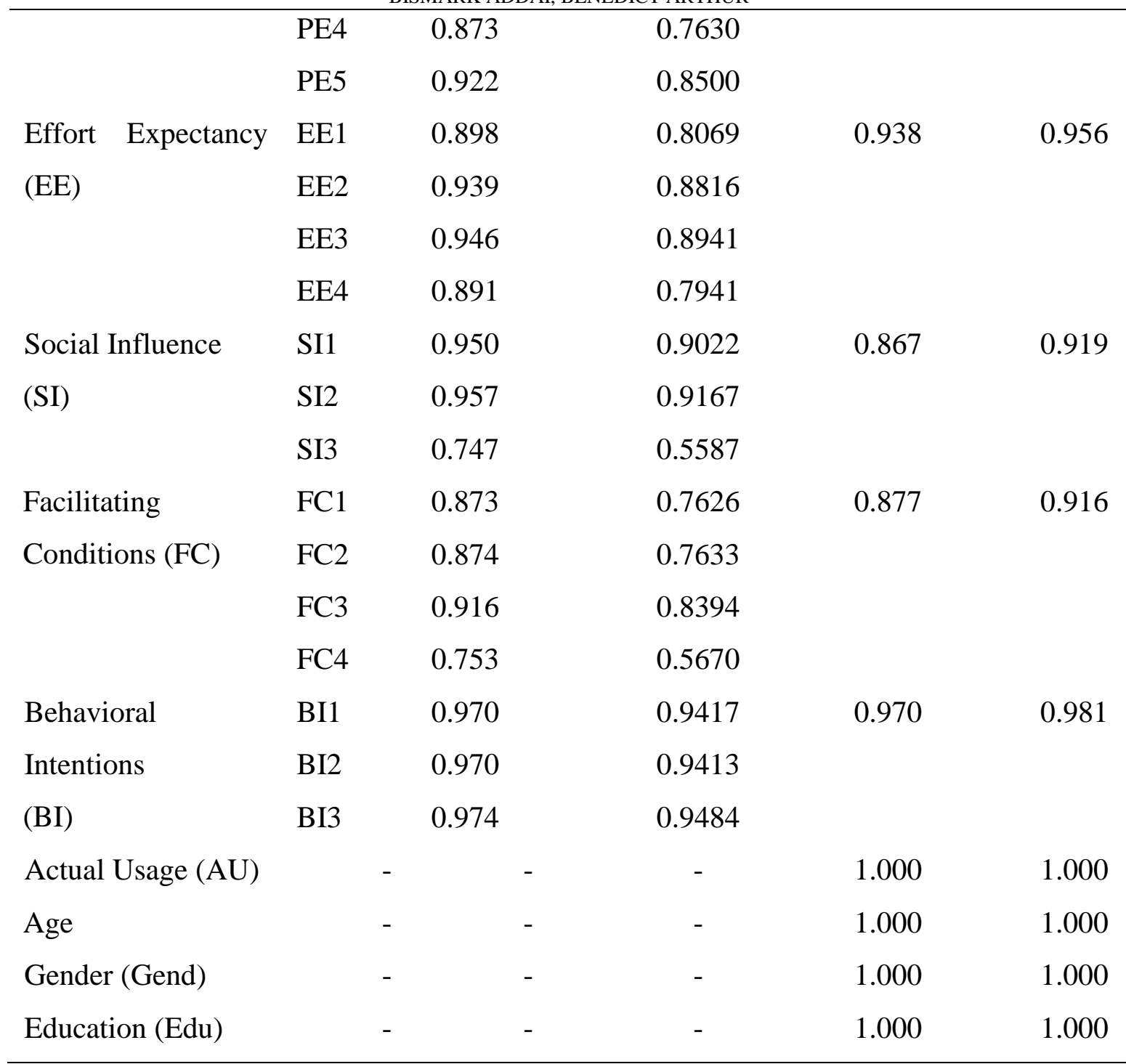

\subsection{Construct validity}

The discriminant and convergent validity tests were done to confirm the validity if the constructs used in this study. The details are explained below.

The convergent validity indicates that the items actually relate to the contracts they measure. According to Hair et al. (2012), there must be high proportion of variance in the building items that measure a given construct. The convergent validity is verified in this study by evaluating the Average Variance Extracted (AVE) of each latent variable. For convergent validity, AVE should be higher than recommended threshold of 0.50 for each construct (Bagozzi and Yi, 1988). It could be seen from Table 3 that all the AVE values are

higher than the recommended threshold of 0.5 , and this confirms that the construct items are related to each other, hence, convergent validity is confirmed.

Another aspect of the construct validity, discriminant validity, was also evaluated in this study. According to Hulland (1999), the discriminant validity shows the extent to which any given construct is special and not necessarily a reflection of other variables. Discriminant validity is estimated by computing the square root of the AVE of a construct and comparing the results with the correlation between the constructs (Fornell and Larcker, 1981). The square root of AVE for a given construct should be greater than the correlation between that construct and other constructs. To verify the discriminant validity, we first consider the values obtained for the square root of AVE written in bold on the diagonal of a correlation table as depicted in Table 3. The AVE value for Behavioral intention (BI) is found to be 0.994 as shown in Table 3 and the square root of the value is 0.971. The square root obtained, which is 0.971 is higher than all the correlation values in Behavioral Intention 
column $(0.170,0.414,0.431,0.614,0.715,0.610,-0.177,0.302,0.263,0.459,0.664,0.803)$ and also exceeds those in the service quality row (0.602). The same thing applies to all the other constructs as well as the interacting variables and all the values reported in Table 3 indicate a well-established construct validity.

Table 3. Construct Validity (square roots of the AVE values boldened in the main diagonal)

\begin{tabular}{llllllll}
\hline & AVE & AU & BI & EE & FC & PE & SI \\
\hline AU & 1.000 & $\mathbf{1 . 0 0 0}$ & & & & & \\
BI & 0.944 & 0.675 & $\mathbf{0 . 9 7 1}$ & & & & \\
EE & 0.844 & 0.629 & 0.715 & $\mathbf{0 . 9 1 9}$ & & & \\
FC & 0.733 & 0.508 & 0.610 & 0.673 & $\mathbf{0 . 8 5 6}$ & & \\
PE & 0.750 & 0.515 & 0.664 & 0.797 & 0.623 & $\mathbf{0 . 8 6 6}$ & \\
SI & 0.793 & 0.659 & 0.803 & 0.768 & 0.717 & 0.776 & $\mathbf{0 . 8 9 0}$
\end{tabular}

\subsection{Evaluation of fitness of the model}

According to Hair et al. (2014), the prediction accuracy or quality of a structural model can be evaluated using any of the following three criteria: the R-square (R2), the Stone-Geisser indicator (Q2), and Goodness of Fit (GoF). According to Cohen (1988), the R2 quality criteria values 0.02, 0.13, and 0.26 indicate small, medium and large respectively. For the Q2 criteria, the values $0.02,0.15$, and 0.35 are considered small, medium and large respectively. According to Akter et al. (2011), the accuracy criteria for the GoF are $0.10,0.25$, and 0.36 for small, medium and large respectively. This study uses the R2 accuracy criteria and Table 4 shows the R square values and the fitness level of accuracy of the research model. The $\mathrm{R}$ square values for the dependent variables, Actual Usage (AU) and Behavioral Intention (BI) are both 0.26 considered large accuracy threshold, this indicates that the model is accurate.

Table 4: R-Square (R2) Coefficient

\begin{tabular}{llcl}
\hline Code & Dependent variable & R-square $\left(\mathbf{R}^{\mathbf{2}}\right)$ & Fit level \\
\hline AU & Actual Usage & 0.471 & Large \\
BI & Behavioral Intention & 0.757 & Large
\end{tabular}

Also, Performance efficiency, effort efficiency and social influence accounts for $75.5 \%$ of the variability in behavioral intention to use the cashless payment system while behavioral intention and facilitating conditions account of $47.1 \%$ of the variability in the actual usage of the cashless system. The result is closely related to the longitudinal validation of UTAUT by Venkatesh et al. (2003) which proved $70 \%$ of the variance in Behavioral Intention to Use and about $50 \%$ in actual use.

\subsection{Structural model assessment and hypotheses testing}

The significance of the constructs in the model and all the hypotheses developed in the study were tested using the Bootstrapping method in the SmartPLS. According to Hair et al. (2013), the results estimated from the bootstrap usually approximate the normality of data and hypothesis with T-values greater than the recommended 1.96 threshold is deemed significant. 
Table 5: Structural model and hypotheses testing

\begin{tabular}{lclll}
\hline Hypotheses & Coefficient (Beta) & T Statistics & P Values & Decision \\
\hline H1: PE -> BI & 0.224 & 2.753 & 0.006 & Supported \\
H2: EE -> BI & 0.124 & 3.141 & 0.002 & Supported \\
H3: SI -> BI & 0.547 & 5.406 & 0.000 & Supported \\
H4: FC->AU & 0.153 & 3.545 & 0.000 & Supported \\
H5: BI -> AU & 0.582 & 14.616 & 0.000 & Supported \\
H6a: Age*PE -> BI & -0.306 & 3.565 & 0.000 & Supported \\
H6b: Age*EE -> BI & -0.224 & 2.480 & 0.013 & Supported \\
H6c: Age*SI -> BI & 0.570 & 8.122 & 0.000 & Supported \\
H7a: Gend*PE -> BI & -0.317 & 2.549 & 0.011 & Supported \\
H7b: Gend*EE -> BI & -0.413 & 3.671 & 0.000 & Supported \\
H7c: Gend*SI -> BI & 0.395 & 5.075 & 0.000 & Supported \\
H8a: Edu*PE -> BI & -0.020 & 0.475 & 0.635 & Not supported \\
H8b: Edu*EE -> BI & 0.013 & 0.349 & 0.727 & Not supported \\
H8c: Edu*SI -> BI & 0.049 & 1.354 & 0.176 & Not supported \\
\hline
\end{tabular}

The path coefficients in Table 5 indicate that 11 (eleven) were statistically significant and they support the hypothetical relationships among the variables developed in this study. That is, hypotheses $\mathrm{H} 1, \mathrm{H} 2, \mathrm{H} 3, \mathrm{H} 4, \mathrm{H} 5$, H6a, H6b, H6c, H7a, H7b and H7c are supported by the structural model. Nevertheless, the structural model does not support the hypotheses H8a, H8b and H8c. Performance efficiency, effort efficiency and social influence were all found to have significant positive influence on the behavioral intention to use the cashless system at $1 \%$ percent significant level with their respective Beta coefficients 0.224, 0.124, and 0.547. The implication here is that behavioral intention of people to use the cashless payment system is strongly driven by performance expectance, effort expectancy and social influence. This finding is consistent with the study of Omol et al. (2016) who found that Perceived Usefulness or performance expectancy significantly affects individual intention to accept the Mobile Money Payments technology in Kenya. Also, the result of this study affirms the finding of Chang et al. (2007); Yakubu (2012); and Phichitchaisopa and Naenna (2013) who also found out that effort expectancy positively influences behavioural intention to use technology. The outcome of the social influence construct in this study differs from the findings of Chang et al. (2007) who found an insignificant impact of social influence on behavioral intention to use technology. However, the result is consistent with Cilliers and Flowerdays (2014); Alaiad and Zhou (2014) who found social influence to be a relevant interpreter of user's behavioural intention to use a new technology.

Facilitating conditions has a significant positive influence on actual usage of the cashless system at $1 \%$ significance level with Beta coefficient of 0.153. This indicates that when all the necessary architecture and the support systems are in place people will use the e-zwich cashless system. Behavioral intention is also found to significantly influence actual usage at significance level of $1 \%$ with Beta coefficient 0.582. This result is consistent with the study of Tabassum et al. (2015) who established that behavioral intention and facilitating conditions such as user's knowledge of search domain, quality of digital library content, system features and service quality directly affect the usage of digital library. 
Gender is found to significantly moderate the relationship between social influence and behavioral intention at 5\% significance level with a positive Beta coefficient 0.395 . On the contrary, gender moderates negatively the relationship between performance efficiency and behavioral intention as well as that of effort efficiency and behavioral intention at $5 \%$ and $1 \%$ significance levels respectively. The interacting effect of gender and the three constructs on the behavioral intention to use the cashless payment system signifies that the intention to use or not to use the e-zwich payment system is largely influenced by the gender of the user. By using discrete values of 1 and 2 to denote males and females respectively similar to the traditional 0/1 dummy in the direction of females, the positive interaction effect of gender and social influence on behavioral intention indicate that females are more likely to be influenced by social image to use the e-zwich cashless system than males. The negative moderation of gender in the relationship between performance expectancy and behavioral intention as well as effort expectancy and behavioral intention also signifies that the gains from performance of a system and the ease of use of the system influences men more than women. This finding affirms the result of Venkatesh et al., 2003 who expounded that females are more tech-phobia or possess higher levels of tech anxiety relatively to their male counterparts. Also, females are more sensitive to the proposals of their peers and therefore the effect of social influence is stronger on them than males.

The moderating effect of education in the relationship between performance expectancy and behavioral intention, effort expectancy and behavioral intention as well as social influence and behavioral intention were all found to be statistically insignificant. The implication is that effect of performance expectancy, effort expectancy and social influence does not depend on the level of education of users. This may be because individuals in Ghana regardless of their educational background easily get acclimatized to the use of a technology and electronic devices that are useful to them and the society as a whole. Therefore, no matter one's education level, the use of basic technology such as the use of mobile phones, debit/credit card, the e-zwich smart card and even how to operate PoS can be easily learned without necessarily having any higher formal education.

Age is found to moderate positively the relationship between social influence and behavioral intention at $1 \%$ significance level with Beta coefficient 0.570 . However, age moderates negatively the relationship between performance efficiency and behavioral intention as well as that of effort efficiency and behavioral intention at $1 \%$ and 5\% significance levels respectively. The moderating effect of age in the relationship between the three constructs and behavioral intention indicates that the intention to use or not to use the e-zwich payment system is largely dependent on the age of the user. The positive moderation of age in the relationship between social influence and behavioral intention implies that even though the aged may not want to use the cashless system, societal recognition and the good image for people using the cashless system can lure even the aged to have the intention to use e-zwich. The negative moderation of age in the relationship between performance expectancy and behavioral intention as well as effort expectancy and behavioral intention signifies that the gains from performance of a system and the ease of use of the system influences younger people more than the aged. This outcome of the study is also in line with the findings of Omol et al. (2017) in Kenya where typical mobile money payment users were found to be relatively young.

Additionally, the moderating effects of age in the relationship between performance efficiency and behavioral intention as well as that effort expectancy and behavioral intention could be further explained in the lenses of the life-cycle theory. The empirical results show that both performance expectancy and effort expectancy influences young people more than old people in their intention to use the cashless system. This means the utility derived by the young people from the cashless system surpasses that of the old people. Individual utility (happiness or satisfaction) is usually assumed to be a function of consumption. Therefore, our empirical results support the life-cycle theory in the sense that young people tend to consume more with the advent of the cashless system than the old people. Even though Nordin et al. (2012) and Omol et al. (2017) documented that the adoption of cashless system causes bankruptcy among the youth because of increasing consumption among them, those studies did not support their findings with any economic theory. 


\subsection{CONCLUSION AND RECOMMENDATION}

In this article, we employ the Unified Theory of Acceptance and Use of Technology (UTAUT) and the structural equation model to estimate users' behavioral intentions and actual usage of the cashless system. The structural results show that eleven out of the fourteen hypotheses are statistically significant while the remaining three are statistically insignificant. The results also indicate that performance efficiency, effort efficiency and social influence significantly influence the behavioral intentions of people to use the cashless system and the three constructs are significantly moderated by the age and gender of users. Behavioral intentions and facilitating conditions are also found to influence actual usage of the cashless system significantly.

In view of the aforementioned findings, the study recommends the following: First, the GhIPSS could upgrade the infrastructure framework of e-zwich in order to transform intended desires of the populace to use ezwich into actual usage since facilitating conditions have a significant impact on actual usage of the cashless system. The upgrade could include the use of QR codes and mobile applications for e-zwich transactions; availability of PoS machines at vantage points such as markets, bus stations, shopping malls, hospitals, schools, filling stations, stadia to facilitate 24/7-hour accessibility to users' money. The mobile phone interface will provide high sense of convenience and user friendliness to users especially the youth who are the largest populace increasingly embracing smart phones as part of their daily life. Also, the e-zwich card can be given a generic feature such as the VISA cards to enable usage in any available ATM at any time of convenience to users. The incorporation of these mobile app and ATM like card features will help reduce the level of tech anxiety particularly in female users to wholly embrace and utilize the e-zwich for their daily financial activities. Second, there should be massive publicity on the proposed features and benefits of e-zwich through both printed and electronic media to deepen public interest and awareness in order to realize the significant role social influence plays in the adoption of e-zwich. Having established that the role of social influence in e-zwich adoption is stronger among the youth and females, e-zwich advertisements should target the youth and women.

Finally, the current study is limited to five metropolises in Ghana and future studies could incorporate holders of the e-zwich smart card and PoS across Ghana. Also, we dropped the moderating effect of demography in the relationship between facilitating conditions and actual usage of the cashless system because of the challenges we encountered in using the SmartPLS to model many moderators. Thus, there is an avenue for future research to include the moderating effects of demography in the relationship between facilitating conditions and actual usage of a cashless system applying the UTAUT model or other broad technology acceptance models especially when more information becomes available on the applicability of the SmartPLS or similar application in employing many moderators in the relationships among constructs.

\section{REFERENCES}

ACCRA DAILY MAIL. E-zwich Roll out Plan Revised in Ghana, 2010. Retrieved from www.mweb.com on December 28, 2019.

ACKORLIE, C. Business and Financial Times, Banking Survey, 2009.

ALAIAD, A., and ZHOU, L Patients' behavioral intention toward using healthcare robots. In Proceedings of the19th Americas Conference on Information Systems (pp. 1-11), 2013.

AJZEN, I. From intentions to actions: A theory of planned behavior. In Action control (pp. 11-39). Springer, Berlin, Heidelberg, 1985. 
AJZEN, I., and FISHBEIN, M. Attitude-behavior relations: A theoretical analysis and review of empirical research. Psychological Bulletin, 1977, 84(5), 888-918.

BAGOZZI, R.P. and Yi, Y. On the evaluation of structural equation models. Journal of the Academy of Marketing Science, 1988, 16(1): 74-94.

BANK OF GHANA. Notice on Mobile Money Transactions, 2012. Retrieved from bog.gov.

BENNANI, A., and OUMLIL, R. Factors fostering IT acceptance by nurses in Morocco. International Conference on Research Challenges in Information Science, Paris: France, 2013.

CHANG, I., HWANG, H., HUNG, W., and LI, Y. Physicians' acceptance of pharmacokinetics-based clinical decision support systems. Expert Systems with Applications, 2007, 33(2), 296-303.

CHINA BRIEFING. China to Increase Domestic Demand by Smoothing Consumption of Information - Guofa, 2013: No. 32, August 19. Retrieved from https://www.china-briefing.com/news/china-to-boost-domesticdemand-by-facilitating-information-consumption/

CILLIERS, L., and FLOWERDAY, S. User acceptance of telemedicine by health care workers a case of the Eastern Cape Province, South Africa, 2014. The Electronic Journal of Information Systems in Developing Countries, 65(1), 1-10.

CIRASINO, M., and GARCÍA, J. A. Measuring payment system development. Payment Systems Policy and Research, Financial Infrastructure Series, World Bank, Washington, DC, 2008.

COHEN J. Statistical power analysis for the behavioral sciences. Hillsdale, NJ: Erlbaum, 1988.

DAVIS, F.D. A technology acceptance model for empirically testing new end-user information systems: Theory and result. PD.D. dissertation, Sloan School of Management, Massachusetts Institute of Technology, 1986.

E-ZWICH. "National Switch" (e-zwich), 2010. Available at: http://www.e-zwich.com/index1.php?linkid=324. Accessed on March 11, 2019.

FANG, X., CHAN, S., BRZEZINSKI, J., XU, S. Moderating effects of task type on wireless technology acceptance. Journal of Management Information Systems, 2005, 22(3), 123-157.

FIGL, K., and DERNTL, M. The impact of perceived cognitive effectiveness on perceived usefulness of visual conceptual modeling languages. In International Conference on Conceptual Modeling (pp. 78-91). Springer, Berlin, Heidelberg, 2011.

FOREXBONUSES Survey report. The World's Top 10 Cashless Nations in 2017. Retrieved from: http://www.forexbonuses.org/cashless-countries/

FORNELL, C., LARCKER, D. F. Evaluating structural equation models with unobservable variables and measurement error. Journal of Marketing Research, 1981, 18(1): 39-50.

HAIR, J. F., HULT, G. T. M., RINGLE, C. M., SARSTEDT, M. A primer on partial least squares structural equation modeling (PLS-SEM). Thousand Oaks: Sage, 2013. 
CA: Sage, 2014.

. A primer on partial least squares structural equation modeling (PLS-SEM). Los Angeles,

HAIR, J. F., SARSTEDT, M., PIEPER, T. M., RINGLE, C. M. The use of partial least squares structural equation modeling in strategic management research: A review of past practices and recommendations for future applications. Long Range Planning, 2012, 45(5-6): 320-340.

HULLAND, J. Use of partial least squares (PLS) in strategic management research: A review of four recent studies. Strategic Management Journal, 1990, 20(2): 195-204.

INTERNATIONAL FINANCIAL CORPORATION (IFC). 2013.

KENYA Country Profile. Enterprise Surveys, 2013. Retrieved April 9, 2019 from http://www.enterprisesurveys.org.

KHAYATI, S., AND ZOUAOUI, S. K. Perceived usefulness and use of information technology: The moderating influences of the dependence of a subcontractor towards his contractor. Journal of Knowledge Management, Economics and Information Technology, 2013, 3(6), 68-77.

MASTER CARD PRESS RELEASE ARCHIVE. MasterCard-Branded National e-ID Card Launched in Nigeria, 2014. Retrieved from: https://newsroom.mastercard.com/mea/press-releases/nigerian-national-e-id-card.

MODIGLIANI, F. \& BRUMBERG, R. Utility Analysis and Aggregate Consumption Functions: An Attempt at Integration. Post Keynesian Economics. New Brunswick. Rutgers University, 1954.

NATIONAL COMMUNICATIONS AUTHORITY. Industry Information - Telecom Subscriptions, May, 2019. Retrieved from: https://www.nca.org.gh/assets/Uploads/Industry-Information-as-at-May-2021.

NOORDIN N., ZAKARIA Z, SAWAL, M., HILMIE, M. Z., NGAH, K., HUSSIN, Z. H. Bankruptcy among young executives in Malaysia. Intrern. Conf. Econ. Mark. Manag, 2012, 28:132-136.

OMOL, E., ABEKA, S. and WAUYO, F. Factors Influencing Acceptance of Mobile money Applications in Enterprise Management: A Case Study of Micro and Small Enterprise Owners in Kisumu Central Business District, Kenya. International Journal of Advanced Research in Computer and Communication Engineering, 2017. Vol. 6.

PHICHITCHAISOPA, N., and NAENNA, T. Factors affecting the adoption of healthcare information technology. EXCLI Journal, 2013, 12, 413-436.

PYNOO, B., DEVOLDER, P., DUYCK, W., VAN BRAAK, J., SIJNAVE, B., DUYCK, P. Do hospital physicians' attitudes change during PACS implementation? A cross-sectional acceptance study. International journal of medical informatics, 2012, 81(2), 88-97.

ROGERS, E. Diffusion of Innovations. New York, NY: Free Press, 1995.

SHIBL, R., LAWLEY, M., \& DEBUSE, J. Factors influencing decision support system acceptance. Decision Support Systems, 2013, 54(2), 953-961. 
TABASSUM, M., ROKNUZZAMAN, M., \& ISLAM, M. M. Usage of a digital library system at a private university library in Bangladesh. Annals of Library and Information Studies (ALIS), 2015, 62(2), 94-103.

THOMPSON, R. L., HIGGINS, C. A., and Howell, J.M. Personal computing: Toward a conceptual model of utilization. MIS Quarterly, 1991, 15(1), 125-143.

VENKATESH, V., and DAVIS, F. D. A theoretical extension of the technology acceptance model: Four longitudinal field studies. Management Science, 2000, 46(2), 186-204.

VENKATESH, V., MORRIS, M. G., DAVIS, G. B., and DAVIS, F. D. User acceptance of information technology: Toward a unified view. MIS Quarterly, 2003, 27(3), 425-478.

YAKUBU, A. W. The adoption and use of electronic payment systems in Ghana, a case of e-zwich in the Sunyani municipality. BUSINESS, C. E. M. I. Doctoral dissertation, Institute Of Distance Learning, Kwame Nkrumah University of Science and Technology, 2012. 